\title{
Selective Exploration and Experimental Research of a New Filling Cementitious Material
}

\author{
Li Xin ${ }^{1,2}$, Guo Lijie ${ }^{1,2^{*}}$, Xu Wenyuan ${ }^{1,2}$ and Li Wenchen \\ ${ }^{1}$ BGRIMM Technology Group, Beijing 102628, China \\ ${ }^{2}$ National Center for International Joint Research on Green Metal Mining, Beijing 102628, China
}

\begin{abstract}
The method of stage vacant place and subsequent filling has been used in an iron mine in Anhui province, but the effect of underground filling with local cement dose not meet the requirements. Therefore, the cementitious material was developed which suitable for the actual situation of the mine. In this paper, the basic properties, fluidity of filling slurry and strength of filling body between local cement and cementitious materials are compared and studied. The experimental results show that the diffusion of filling slurry with new cementitious material is higher $37.93 \%$ than the filling slurry with local cement, and the compressive strength of filling body is higher $75.82 \%$ than the filling body with local cement. The testing indexes of the new cementitious material are better than the local cement. Therefore, the new cementitious material for mining can be well adapted to the cemented filling of tailings in this mine. Through the comparative experimental study in this paper, the data support and theoretical basis of performance evaluation and industrial application are provided for mine filling cementitious materials.
\end{abstract}

\section{Introduction}

A mine was built in Anhui Province in 2008 and the dressing ability was designed to 4.5 million $\mathrm{t} / \mathrm{a}$, the ore bodies is large and thick, the average grade is $31 \%$ and the value of the ore is high. The main mining method is stage open stoping and subsequent filling. Because of the quality and strength of filling body is one of the important factors influencing the production of mine, gelling material plays a main role in the aspect of the strength of filling body. So, the chosen of cementitious material which suitable foiyr the actual situation of mine is particularly important. ${ }^{[1,2]}$

At present, the cementitious material of mine filling is bought from local cement plant, but in the actual work, the strength of backfill is generally low, the cement consumption is high. In order to improve the filling effect, improve the quality of backfill and save the cost of filling, according to the characteristics of the unclassified tailings, the cementitious material was developed by the mine that adapted to the tailings.

The contrast experiments about the basic performance, fluidity of slurry and strength of filling body were carried on to the local cement and new developed cementitious material. So the basic data support can be provided to the rating of cementitious material merit and industrial application though the contrast experiments.

In this paper, the local cement is identified as cement $A$, the new cementitious material is identified as cement $\mathrm{B}$; The slurry made by cement $\mathrm{A}$ is identified as slurry A, the slurry made by cement $B$ is identified as slurry $B$; the backfill formed by slurry $\mathrm{A}$ is identified as backfill $\mathrm{A}$, the backfill formed by slurry B is identified as backfill B.

\section{The basic physicochemical characteristics of unclassified tailings}

\subsection{The physical property parameters of unclassified tailings}

The density, bulk density and porosity of unclassified tailings were tested and the results are shown in Table 1.

Table 1 . The physical property of unclassified tailings

\begin{tabular}{cccc}
\hline Material name & Density g/cm3 & Bulk density g/cm3 & Porosity $/ \%$ \\
\hline Unclassified tailings & 2.87 & 1.58 & 44.95 \\
\hline
\end{tabular}

\footnotetext{
*Corresponding author's e-mail: guolijie@bgrimm.com
} 


\subsection{The chemical component of unclassified tailings}

The chemical composition of tailings are tested by using method of fluorescence, the results are shown in Table 2. As the result, the main metal and metal oxide are $\mathrm{Fe}$, $\mathrm{Al}_{2} \mathrm{O}_{3}, \mathrm{CaO}$ and $\mathrm{MgO}$, the content is $7.94 \%, 5.84 \%, 3.67 \%$ and $4.17 \%$ respectively; the non-metallic and non-metal oxide are $\mathrm{SiO}_{2}, \mathrm{~S}$ and $\mathrm{P}$, the content is $65.75 \%, 0.18 \%$ and $0.05 \%$ respectively. As the; result of chemical composition, we can get that The main components of the tailings is $\mathrm{SiO}_{2}$, it belongs to the high silicon iron tailings; with the low content of sulfur and sulfide, phosphorus and phosphide, so the they have less influence to backfilling.

Table 2. The percentage composition of Chemical elements and oxides

\begin{tabular}{cccccc}
\hline Chemical component & $\mathrm{SiO}_{2}$ & $\mathrm{Al}_{2} \mathrm{O}_{3}$ & $\mathrm{CaO}$ & $\mathrm{MgO}$ & $\mathrm{Fe}$ \\
\hline Percentage omposition $/ \%$ & 65.75 & 5.84 & 3.67 & 4.17 & 7.94 \\
\hline Chemical component & $\mathrm{S}$ & $\mathrm{P}$ & $\mathrm{Na}$ & $\mathrm{Mn}$ & $\mathrm{K}$ \\
\hline Percentage composition $/ \%$ & 0.18 & 0.05 & 0.38 & 0.03 & 1.35 \\
\hline
\end{tabular}

\subsection{Particle size analysis of unclassified tailings}

The test for granularity of unclassified tailings by using malvern laser particle analyzer, particle size distribution are shown in Figure 1.

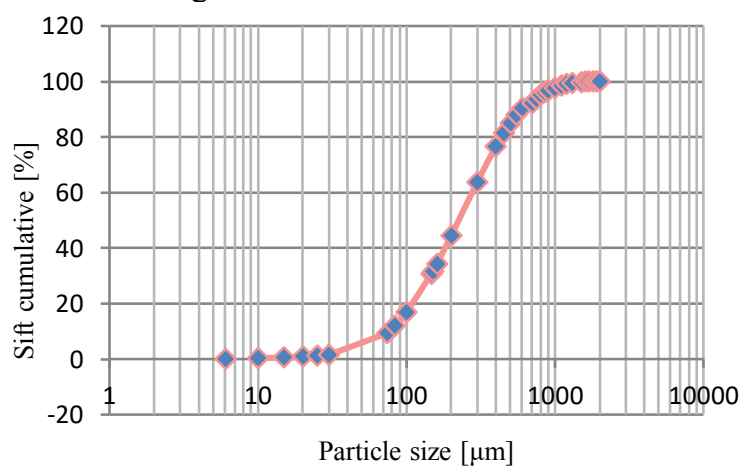

Figure 1. Particle size distribution of unclassified tailings

According to the grade of tailings, the uniformity of it can be said with non-uniform coefficient $\alpha$, the calculation formula is:

$$
\alpha=d_{60} / d_{10}
$$

In the form, $\mathrm{d}_{10}$ is the diameter that ten percent of total sand through the sieve; $d_{60}$ is the diameter that sixty percent of total sand through the sieve ${ }^{[3,4]}$. As the result, $\mathrm{d}_{10}$ is $75.996 \mu \mathrm{m}, \mathrm{d}_{60}$ is $281.617 \mu \mathrm{m}$, and the non-uniform coefficient of particle size composition $\alpha$ is 3.71 .

As the analysis of result, fine particles contains of unclassified tailings is less, it belongs to the type of the relative lack of fine particles; the natural grading of tailings is discontinuous gradation.

\section{The basic properties of cementitious material}

Samples of cement A and cement B were taken in the different time and tested according to the cement testing standard GB175-2007, the result are shown in Table 3.

Table 3. The test results of fundamental nature of cementitious material

\begin{tabular}{cccccc}
\hline Material name & $\begin{array}{c}\text { Fineness(sieve residue } \\
45 \mu \mathrm{m}) / \%\end{array}$ & $\begin{array}{c}\text { Initial setting } \\
\text { time } / \mathrm{min}\end{array}$ & $\begin{array}{c}\text { Final setting } \\
\text { time } / \mathrm{min}\end{array}$ & $\begin{array}{c}\text { Bending strength of } \\
\text { 28days } / \mathrm{MPa}\end{array}$ & $\begin{array}{c}\text { Compressive strength of } \\
\text { 28days } / \mathrm{MPa}\end{array}$ \\
\hline Cement A & 11.0 & 244 & 314 & 6.6 & 31.5 \\
Cement B & 8.0 & 162 & 203 & 7.6 & 32.8 \\
Standard of & $\leq 30$ & $\geq 45$ & $\leq 390$ & 6.5 & 32.5 \\
32.5 cement & & & & \\
\hline
\end{tabular}

It is shown that in table 3 , the $45 \mu \mathrm{m}$ sieve residue and setting time of cement $\mathrm{A}$ and cement $\mathrm{B}$ are up to the standard of 32.5 cement, bending strength and compressive strength of cement B are higher than cement A. The initial setting time and final setting time of cement B are shorter than cement A. The result of actual application is that the setting and hardening time of backfill B are shorter than backfill A. The strength formed earlier can help to improve the efficiency of filling and mining.

\section{The contrast of rheological properties for slurry}

The Slurry rheological characteristics and influencing factors are the foundation and the important basis of parameter optimization design for the preparation of slurry, the calculation of pipe resistance and the pipeline system ${ }^{[5]}$. The contrast and evaluation will be carried on to slurry A and slurry B from the slump and the dispersion degree experiments in this paper.

\subsection{The experiment of slump}

Slump is referenced to the concept from the concrete of high concentration filling, it is mainly used for characterization of flowing property of high density filling. The slump directly reflects the flow state and friction resistance of slurry. Confirmed by research, slump value mainly depends on the grading of solid particle in the slurry and slurry concentration. The mechanical meaning is: the final deformation of the slurry flow by gravity, due to internal resistance and stop. 
The result of slump directly reflects the stand or fall of liquidity and the size of the resistance to flow of, the value of slump is higher, the flowing property of slurry is better and flow resistance is smaller. By measuring the resistance loss with the change of slump confirmed that: when the slump is less than 15 to $17 \mathrm{~cm}$, the increased speed of resistance loss is faster with the decrease of slump, usually, slump value of pumping filling material to maintain in $15-20 \mathrm{~cm}^{[6,7]}$.

The tests of slump were carried on to slurry a and slurry B with different concentrations and different sandcement ratio, the result are shown in Table 4, and the curve of slump to slurry concentration and sand-cement ratio can be fitted out, as shown in Figure 2.

Table 4. Test results of slump /cm

\begin{tabular}{ccccccc}
\hline \multirow{2}{*}{$\begin{array}{c}\text { Slurry } \\
\text { type }\end{array}$} & $\begin{array}{c}\text { Slurry concentration } \\
\text { /\% }\end{array}$ & \multicolumn{5}{c}{ Sand-cement ratio } \\
\cline { 3 - 7 } & 72 & 25.08 & 21.28 & 16.98 & 12.79 & 9.38 \\
Slurry A & 74 & 24.27 & 18.27 & 16.27 & 9.17 & 9.27 \\
& 76 & 24.27 & 16.77 & 15.47 & 8.27 & 6.07 \\
\hline \multirow{3}{*}{ Slurry B } & 72 & 24.77 & 18.37 & 16.47 & 11.77 & 9.37 \\
& 74 & 22.07 & 17.77 & 15.97 & 10.77 & 9.47 \\
& 76 & 20.77 & 18.27 & 15.27 & 8.27 & 6.97 \\
\hline
\end{tabular}

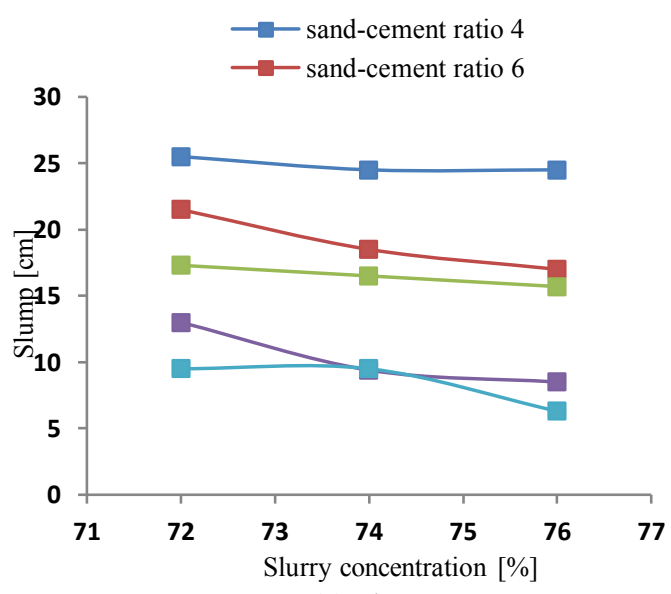

(a) Slurry A

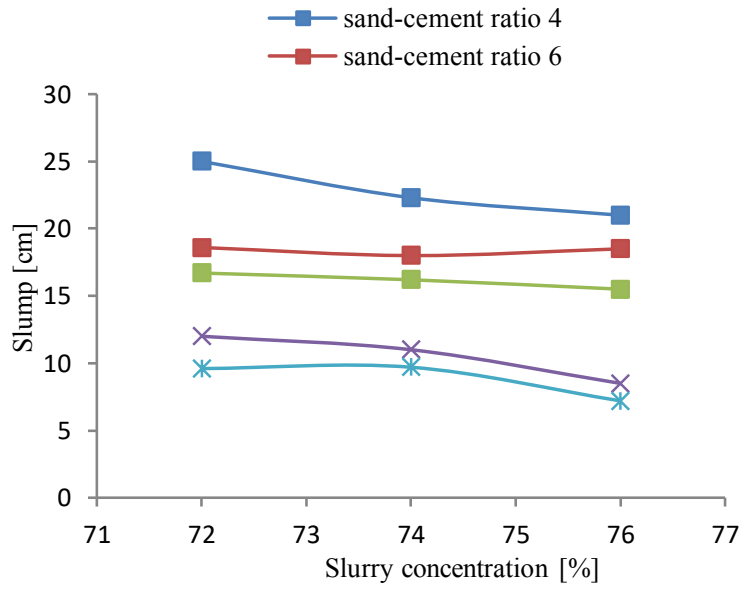

(b) Slurry B

Figure 2. Curve of slump to slurry concentration and sand-cement ratio

As the result we can get that both slumps of slurry A and slurry $B$ are decreases with the increase of concentration and sand-cement ratio, so as the slurry concentration and sand-cement ratio higher the liquidity is worse.

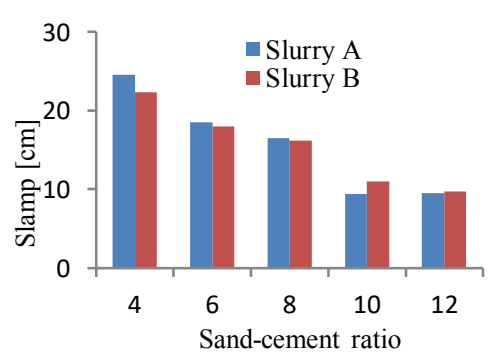

(a) Concentration $72 \%$

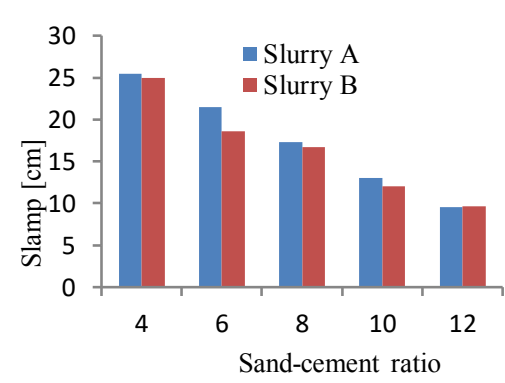

(b) Concentration $74 \%$

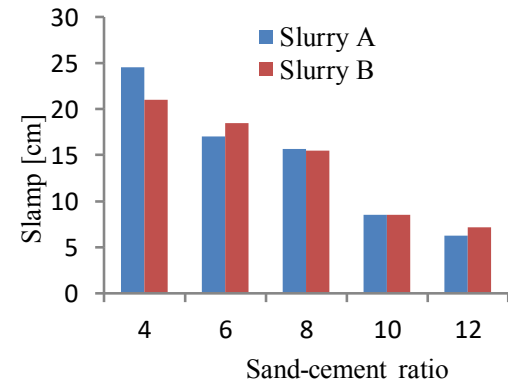

(c) Concentration $76 \%$

Figure 3. Comparison result of slump between slurry A and slurry B

As the result of comparing the slump between slurry A and slurry B, slumps are almost same under the same conditions, the fluidities of slurry are good under the condition of the concentration in $72-76 \%$ and sandcement ratio $\leq 8$. This situation of slurry can satisfy the requirement of mine filling pump. The test is almost impossible to be finished when the slurry concentration less than $72 \%$.
In the case of the same slurry concentration, slumps were compared between slurry A and slurry B, the results are shown in Figure 3.

\subsection{The experiment of diffusion degree}

Diffusion degree is also referenced to the concept from the concrete of high concentration filling to reflect the slurry flow characteristics. If the diffusion of slurry is small, it will be inhaled difficult and with big frictional resistance in transport, so the high pumping pressure will 
be required, and if the situation not disposed of properly there will be a tube jam phenomenon. If the diffusion is too high, the slurry is likely to occur segregation deposition phenomenon, it is not suitable for conveying neither ${ }^{[8]}$.
The tests of diffusion were carried on to slurry A and slurry B with different concentrations and different sandcement ratio, the results are shown in Table 5.

Table 5. Test results of diffusion $/ \mathrm{cm}$

\begin{tabular}{ccccccc}
\hline \multirow{2}{*}{ Slurry type } & Slurry concentration $/ \%$ & \multicolumn{5}{c}{ Sand-cement ratio } \\
\cline { 3 - 7 } & & 4 & 6 & 8 & 10 & 12 \\
\hline \multirow{3}{*}{ Slurry A } & 66 & 18.88 & 18.65 & 17.98 & 15.34 & 14 \\
& 68 & 18.27 & 18.02 & 18.02 & 13.77 & 13.42 \\
& 70 & 17.42 & 17.52 & 16.77 & 14.32 & 12.42 \\
& 72 & 17.37 & 15.79 & 13.72 & 12.17 & 9.82 \\
\multirow{3}{*}{ Slurry B } & 74 & 16.87 & 15.57 & 14.52 & 11.57 & 8.62 \\
& 66 & 25.97 & 24.57 & 20.31 & 18.09 & 16.47 \\
& 68 & 24.02 & 19.77 & 16.12 & 15.87 & 15.07 \\
& 70 & 21.87 & 19.57 & 14.67 & 14.52 & 12.12 \\
& 72 & 20.42 & 16.97 & 14.52 & 13.62 & 11.62 \\
& 74 & 16.97 & 15.42 & 13.82 & 10.67 & 8.37 \\
\hline
\end{tabular}

In the case of the same slurry concentration, diffusance degrees were compared between slurry A and slurry B, the results are shown in Figure 4.

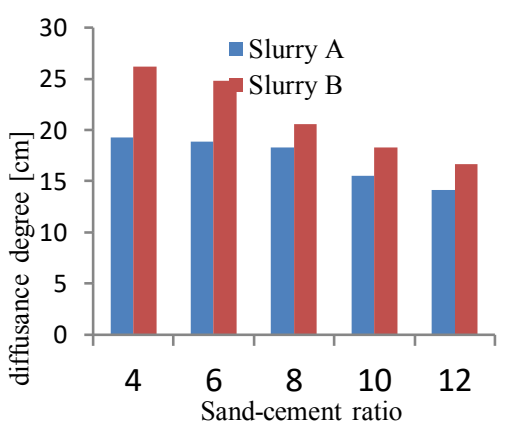

(a) Concentration $66 \%$

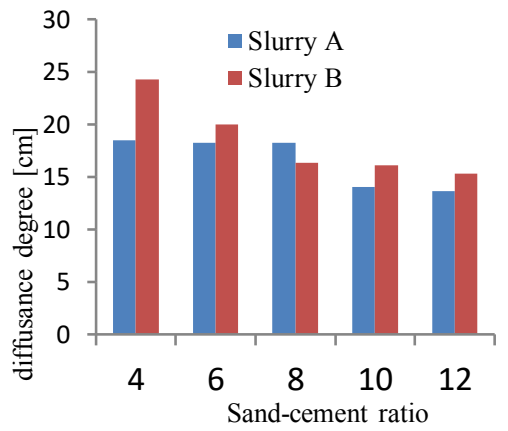

(b) Concentration $68 \%$

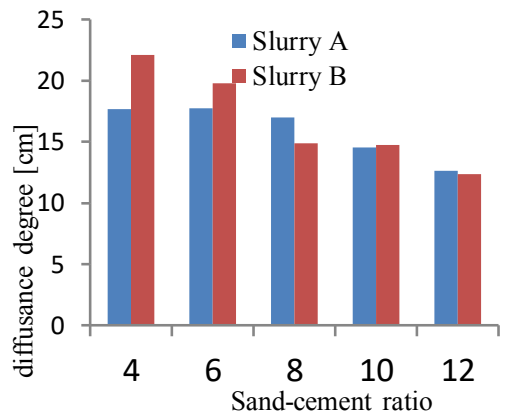

(c) Concentration $70 \%$

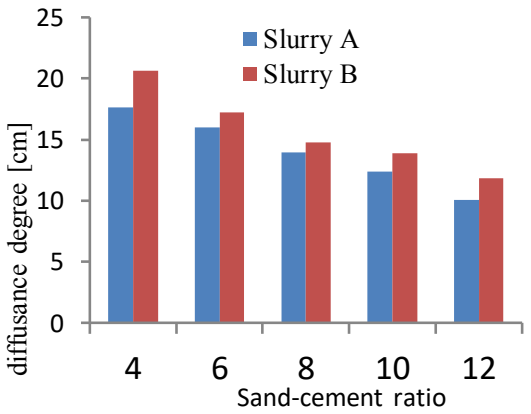

(d) Concentration $72 \%$

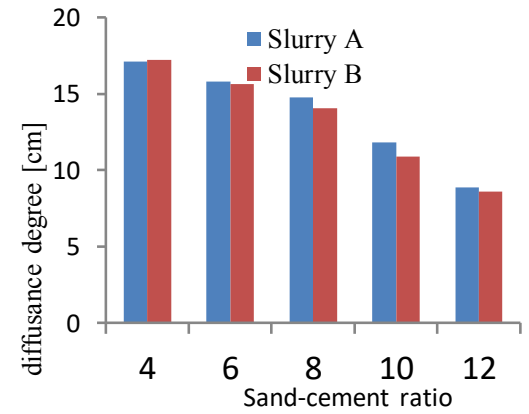

(e) Concentration $74 \%$

Figure 4. Comparison result of diffusion between slurry A and slurry B

As a results, diffusion degree gradually become smaller with the slurry concentration and sand-cement ratio increased. That with the increase of cementitious material proportion in the slurry, the diffusion degree increases gradually, this is because the fine particles in cementitious material mixes with sand and the fine particles play a role of lubrication. By contrast, the diffusion effect and liquidity of slurry B are better than slurry A.

\section{The comparison for strength performance of backfill}

The strength of filling body can directly influence the ore body safety and continuous mining. Therefore, the analysis of the influencing factors to the strength of filling body is great significance. Practice has proved that the main influencing factors to the strength of filling body are sand-cement ratio, concentration of slurry and aggregate gradation, etc. In order to reach expected 
requirements of the strength to the backfill, chosen the right filling materials that fitting to features of tailings and good quality are very important. So, the comparison experiment between backfill A and backfill B were carried on.

\subsection{Experimental method and experimental results}

The main influencing factors to the experiment of strength of filling body are sand-cement ratio and concentration of slurry [9]. Slurry concentration was designed to $66 \%, 68 \%, 70 \%, 72 \%$ and $75 \%$; sand-cement ratio was designed to $4,6,8,10$ and 12 ; uniaxial compressive strength experiment was carried out according to the curing age of 7 days, 28 days and 60 days respectively. With reference to the compressive strength test method of concrete, casting block, using the joint filling to mould making filling blocks on the size of $7.07 \times 7.07 \times 7.07 \mathrm{~cm}^{[10]}$.

The calculating formula of compressive strength of filling body is ${ }^{[11]}$ :

$$
R_{n}=10 \times \frac{F}{S}
$$

In the formula, $R_{n}$ is the limit compressive strength of the filling block after curing $\mathrm{n}$ days, Mpa; $F$ is the maximum load when filling block was damaged, $\mathrm{kN}$; $S$ is the cross-sectional area of perpendicular to the loading direction of filling block, $\mathrm{cm}^{2}$.

The experimental results are shown in Table 6. In curing age 28 days as the example, experimental results were fit out, the relationship of backfill strength to slurry concentration and sand-cement ratio are shown in Figure 5.

Table 6. The results of uniaxial compressive strength / $\mathrm{MPa}$

\begin{tabular}{|c|c|c|c|c|c|c|c|}
\hline \multirow{2}{*}{ Backfill type } & \multirow{2}{*}{ Curing age /d } & \multirow{2}{*}{ Slurry concentration $/ \%$} & \multicolumn{5}{|c|}{ Sand-cement ratio } \\
\hline & & & 4 & 6 & 8 & 10 & 12 \\
\hline \multirow{15}{*}{ Backfill A } & \multirow{5}{*}{7} & 66 & 0.378 & 0.128 & 0.021 & 0.013 & 0.003 \\
\hline & & 68 & 0.422 & 0.171 & 0.055 & 0.038 & 0.027 \\
\hline & & 70 & 0.503 & 0.22 & 0.103 & 0.063 & 0.049 \\
\hline & & 72 & 0.622 & 0.276 & 0.146 & 0.087 & 0.07 \\
\hline & & 74 & 0.871 & 0.373 & 0.16 & 0.121 & 0.097 \\
\hline & \multirow{5}{*}{28} & 66 & 1.044 & 0.588 & 0.352 & 0.205 & 0.135 \\
\hline & & 68 & 1.053 & 0.612 & 0.39 & 0.242 & 0.183 \\
\hline & & 70 & 1.244 & 0.747 & 0.551 & 0.285 & 0.232 \\
\hline & & 72 & 1.835 & 0.894 & 0.576 & 0.376 & 0.291 \\
\hline & & 74 & 2.722 & 1.115 & 0.614 & 0.49 & 0.36 \\
\hline & \multirow{5}{*}{60} & 66 & 1.344 & 0.635 & 0.58 & 0.446 & 0.312 \\
\hline & & 68 & 1.574 & 0.871 & 0.642 & 0.513 & 0.384 \\
\hline & & 70 & 1.967 & 1.126 & 0.8 & 0.58 & 0.401 \\
\hline & & 72 & 2.523 & 1.348 & 0.876 & 0.647 & 0.418 \\
\hline & & 74 & 3.664 & 1.681 & 0.912 & 0.748 & 0.583 \\
\hline \multirow{15}{*}{ Backfill B } & \multirow{5}{*}{7} & 66 & 0.187 & 0.066 & 0.024 & 0.014 & 0.012 \\
\hline & & 68 & 0.283 & 0.179 & 0.064 & 0.036 & 0.005 \\
\hline & & 70 & 0.414 & 0.207 & 0.102 & 0.056 & 0.024 \\
\hline & & 72 & 0.58 & 0.241 & 0.168 & 0.075 & 0.045 \\
\hline & & 74 & 0.895 & 0.502 & 0.385 & 0.101 & 0.08 \\
\hline & \multirow{5}{*}{28} & 66 & 1.134 & 0.711 & 0.438 & 0.324 & 0.277 \\
\hline & & 68 & 1.397 & 0.863 & 0.547 & 0.406 & 0.285 \\
\hline & & 70 & 1.729 & 1.052 & 0.724 & 0.5 & 0.331 \\
\hline & & 72 & 1.999 & 1.187 & 0.953 & 0.606 & 0.416 \\
\hline & & 74 & 2.804 & 1.39 & 1.125 & 0.788 & 0.589 \\
\hline & \multirow{5}{*}{60} & 66 & 1.535 & 1.166 & 0.797 & 0.428 & 0.323 \\
\hline & & 68 & 1.755 & 1.292 & 0.87 & 0.528 & 0.372 \\
\hline & & 70 & 1.974 & 1.417 & 0.944 & 0.628 & 0.395 \\
\hline & & 72 & 2.194 & 1.543 & 1.018 & 0.644 & 0.436 \\
\hline & & 74 & 3.656 & 2.412 & 1.167 & 0.807 & 0.695 \\
\hline
\end{tabular}




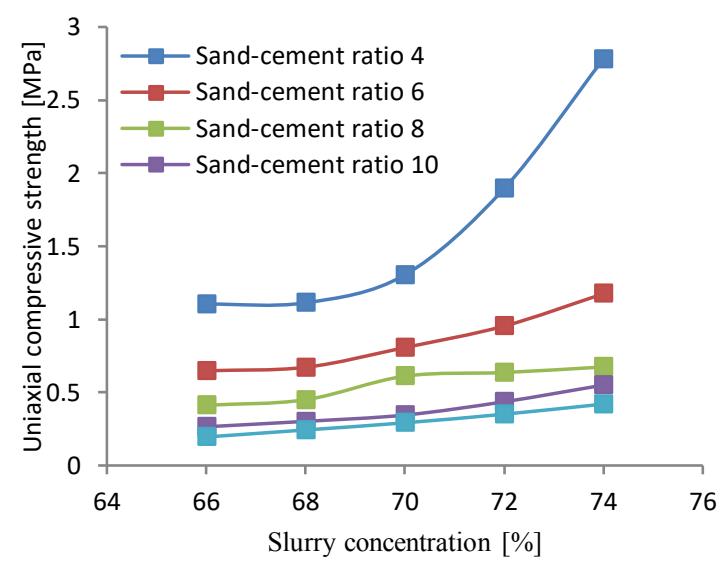

(a) Backfill A

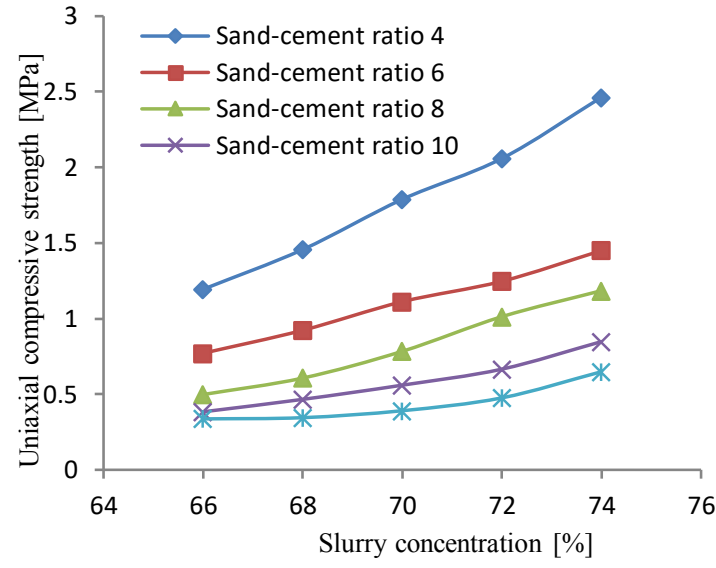

(b) Backfill B

Figure.5 Curve to compressive strength and slurry concentration

Contrast compressive strength between backfill A and backfill B, the result is shown in Figure 6 .

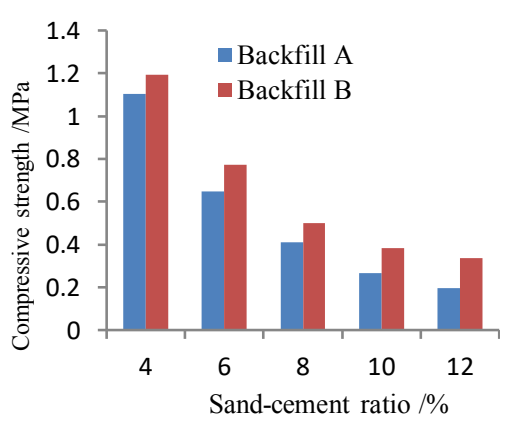

(a) Concentration $66 \%$

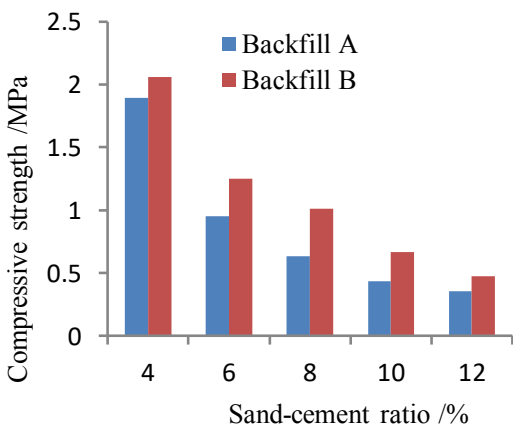

(d) Concentration $72 \%$

$\begin{array}{cc}\text { (d) Concentration } 72 \% & \text { (e) Concentration } 74 \%\end{array}$

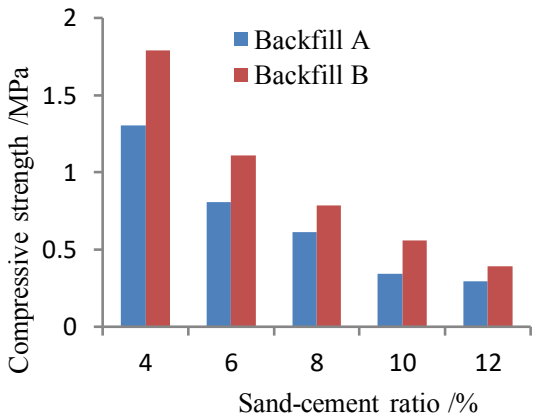

(c) Concentration $70 \%$

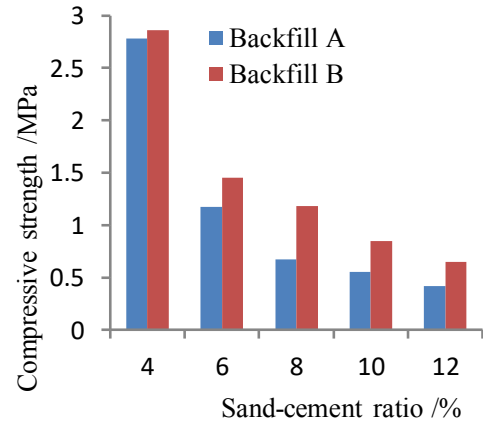

uniaxial compressive strength of backfill B are higher than backfill A 75.82\%.

(3) The general rule between the curing age and uniaxial compressive strength is: the backfill body strength increases with the increase of curing age in a certain time range.

\section{Conclusions}

Based on the comparison experimental research of basic properties, rheological properties and backfill strength between two kinds of cementing materials, and combined with the experimental data analysis to get the following conclusions: 
(1) By the testing results of basic properties to the cementitious materials, except for the uniaxial compressive strength of cement $A$ did not reach the standard, other indicators of cement A and cement B are all up to cement standard of 32.5 rank, the coagulation time, compressive strength and flexural strength of cement $\mathrm{B}$ are batter than cement $\mathrm{A}$.

(2) The rheological properties of slurry reflect the good regularity between the slurry concentration and sand-cement ratio. The diffusion effect and slump effect of two kind of slurry are good, the slumps are almost same, but the diffusion of slurry B is better, the average higher is $9.63 \%$, so we can get that the fluidity of slurry $\mathrm{B}$ is better.

(3) In the same conditions, the uniaxial compressive strength of backfill B are better than backfill A obviously, the average higher is $37.93 \%$, combined the basic test results about two kinds of cementitious materials, the matching to mine tailing of backfill $\mathrm{B}$ are better than backfill A.

(4) The rheological properties of slurry and compressive strength of backfill which made by cementitious material $\mathrm{B}$ are better than cementitious material $\mathrm{A}$, so the cementitious material $\mathrm{B}$ was recommend in mine filling.

\section{Acknowledgments}

This research was financially supported by the National Key Research and Development Project of China (No. 2017YFE0107000) and the Scientific Research Fund of Beijing General Research Institute of Mining and Metallurgy Technology Group (No. JTKJ1807).

\section{References}

1. Tikov B, Mostafa B. (2008) Design and application of underground mine paste backfill technology. J. Geotechnical and Geological Engineering., 26(2): 147-174.

2. Yu Runcang. (2010) Development and innovation of cemented filling technology in China. J. China Mine Engineering., 39(5): 1-3.

3. Zhang Qinli, Wang Xin-ming. (2008) Hydraulic calculation of gravity transportation pipeline system for backfill slurry. J. Journal of Central South University of Technology., 15(5):645-649.

4. Wang Xinming, LI Jian-xiong, Fan Ping-zhi. (2001) Applied technique of the cemented fill with fly ash and fine sands. J. Journal of Central South University of Technology., 8(3):189-192.

5. Zhang Qinli, Li Xieping, Yang Wei. (2013) Optimization of filling slurry ratio in a mine based on back-propagation neural network. J.Journal of Central South University: Science and Technology., 44(7) : 2868-2874.

6. Deng X, Mirzalan A, (1996) Competitive robot mapping homogeneous markers. J. IEEE Trans on Robotics Automation., 12 (4): 532-542.
7. Jiang Xiuxiang, Bai Zhongmin. (2002) Study and practice on a new type of binder used in underground stope backfilling. J. West-China Exploration Engineering., 14(5): 71-72.

8. Zhang Haijun, Chen Huaili, Liang Tingdong. (2009) Study on improving the early strength of filling. J. Metal Mine., 284-286.

9. Rudd M, Nagaratnam S. (2007) Geotechnical properties of cemented paste backfill from Cannington Mine, Australia. J. Geotechnical and Geological Engineering., 25: 383-393.

10. Ercikdi B, Kesimal A, Cihangir F. (2009) Cemented paste backfill of sulphide-rich tailings: Importance of binder type and dosage. J. Cement and Concrete Composites., 31(4): 268-274.

11. Deng Daiqiang, Gao Yongtao, Wu Shunchuan. (2010) The multivariate analysis of cement classified tailings filling material with orthogonal experiment. J. Journal of Shandong University of Science and Technology., 29(1): 48-57. 